2 Stonebridge PA, Callam MJ, Bradbury AW, Murie JA, Jenkins AM, Ruckley CV. Comparison of long-term survival after successful repair of ruptured and non-ruptured abdominal aortic aneurysm. Br J Surg 1993;80:585-6.

3 Johnston KW, and the Canadian Society for Vascular Surgery Aneurysm Study Group. Nonruptured abdominal aortic aneurysm: six-year follow-up results from the multicentre prospective Canadian aneurysm study.J Vasc Surg 1994;20:163-70

4 Semmens JB, Lawrence-Brown MMD, Fletcher DR, Rouse IR, Holman CDJ. The quality of surgical care project: a model to evaluate surgical outcomes in Western Australia using population-based record linkage. Aust NZ J Surg 1998;68:397-403.

5 International Classification of Diseases. Manual of the international statistical classification of diseases, injuries, and causes of death. Geneva: World Health Organisation, 1977.

6 International Classification of Procedures in Medicine. Geneva: World Health Organisation, 1978.

7 The Official National Coding Centre Australian version of ICD-9-CM. Tabular list of diseases, 1st ed. Sydney: National Coding Centre, Faculty of Health Sciences, University of Sydney, 1995.

8 The Official NCC Australian Version of ICD-9-CM. Tabular list (annotated) and index of procedures, 1st ed. Sydney: National Coding Centre, Faculty of Health Sciences, University of Sydney, 1995.

9 Semmens JB, Norman PE, Lawrence-Brown MMD, Bass AJ, Holman CDJ. A population-based record linkage study: the incidence of abdominal aortic aneurysms in Western Australia for 1985-94. Br J Surg 1998;85:648-52.

10 Soreide O, Lillestol J, Christensen O, Grimsgaard C, Myhre HO, Solheim $\mathrm{K}$, et al. Abdominal aortic aneurysms: survival analysis of four hundred and thirty-four patients. Surgery 1982;91:188-93.

11 Thomas PRS, Stewart RD. Abdominal aortic aneurysm. Br J Surg 1988;75:733-6.

12 Campbell W. Mortality statistics for elective aortic aneurysms. Eur J Vasc Surg 1991;5:111-3

13 Muluk SC, Gertler JP, Brewster DC, Cambria, RP, LaMuraglia GM, Moncure AC, et al. Presentation and patterns of aortic aneurysms in young patients. J Vasc Surg 1994:20:880-8.

14 Ederer F, Axtell LM, Cutler SJ. The relative survival rate: a statistical methodology. Natl Cancer Inst Monogr 1961;6:101-21.

15 Hakulinen T. Cancer survival corrected for heterogeneity in patient withdrawal. Biometrics 1982;38:933-42.

16 Esteve J, Benhamou E, Croasdale M, Raymond L. Relative survival and the estimation of net survival: elements for further discussion. Stats Med 1990;9:529-38.

17 Therneau T, Sicks J, Bergstralh E, Offord J. Expected survival based on hazard rates. Rochester, Minnesota: Mayo Clinic, 1994. Technical report number 52
18 Hakulinen T, Tenkanen L, Abeywickrama KH, Paivarinta L. Testing equality of relative survival patterns based on aggregated data. Biometrics 1987;43:313-25.

19 Feinglass J, Cowper D, Dunlop D, Slavensky R, Martin GJ, Pearce WH. Late survival risk factors for abdominal aortic aneurysm repair: experience from fourteen department of veterans affairs hospitals. Surgery 1995;118:16-24

20 Koskas F, Kieffer E. Long-term survival after elective repair of infrarenal abdominal aortic aneurysm: results of a prospective multicentric study. Ann Vasc Surg 1997;11:473-81.

21 Roger VL, Ballard DJ, Hallet JW, Osmundson PJ, Puetz PA, Gersh BJ. Influence of coronary artery disease on morbidity and mortality after abdominal aortic aneurysmectomy: a population-based study, 19711987. J Am Coll Cardiol 1989;14:1245-52.

22 Bowers D, Cave WS. Aneurysms of the abdominal aorta: a 20-year study. JRoy Soc Med 1985;78:812-20.

23 Hallet JW, Naessens JM, Ballard DJ. Early and late outcome of surgical repair for small abdominal aortic aneuyrsms: a population-based analysis. J Vasc Surg 1993;18:684-91.

24 Reigel MM, Hollier LH, Kazmier FJ, O'Brien PC, Pairolero, PC, Cherry Jr $\mathrm{KJ}$, et al. Late survival in abdominal aortic aneurysm patients: the role of the selective myocardial revascularization on the basis of clinical symptoms. J Vasc Surg 1987;5:222-7.

25 Bernstein EF, Dilley RB, Randolph HFI. The improving outlook for patients over 70 years of age with abdominal aortic aneurysms. Ann Surg 1988;207:318-22.

26 Paty PSK, Lloyd WE, Chang BB, Darling RC, Leather RP, Shah DM. Aortic replacement for abdominal aortic aneurysm in elderly patients. $\mathrm{Am} \mathrm{J}$ Surg 1993;166:191-3.

27 Aune S, Amundsen SR, Evjensvold J, Trippestad A. Operative mortality and long-term relative survival of patients operated on for asymptomatic abdominal aortic aneurysm. Eur J Endovasc Surg 1995;9:293-8.

28 O'Hara PJ, Hertzer NR, Krajewski LP. Ten year experience with abdominal aortic aneurysm repair in octogenarians: early results and late outcome. J Vasc Surg 1995;21:830-8.

29 Limet R, Sakalihassan N, Albert A. Determination of the expansion rate and incidence of rupture of abdominal aortic aneurysms. J Vasc Surg 1991;14:540-8.

30 Magee TR, Scott DJ, Dunkley A, St Johnston J, Campbell WP, Baird RN, et al. Quality of life following surgery for abdominal aortic aneurysm. $\mathrm{Br}$ J Surg 1992;79:1014-6.

31 Katz DJ, Stanley JC, Zelenock MD. Gender differences in abdominal aortic aneurysm prevalence, treatment, and outcome. J Vasc Surg 1997;25:561-8.

32 Pleumeekers H, Hoes A, Van Der Does E, van Urk H, Hofman A, de Jong PTVM, et al. Aneurysms of the abdominal aorta in older adults. Am J Epidemiol 1995; 142:1291-9.

(Accepted 11 June 1998)

\title{
Effect of sex of fetus on asthma during pregnancy: blind prospective study
}

\author{
N Beecroft, G M Cochrane, Heather J Milburn
}

United Medical and Dental Schools of Guy's and St

Thomas's Hospital, Guy's Campus, London SE1 9RT

$\mathrm{N}$ Beecroft,

medical student

Department of

Respiratory

Medicine and

Allergy, Guy's

Hospital, London

SE1 9RT

G M Cochrane,

consultant physician

Heather J Milburn,

consultant physician

Correspondence to: Dr H J Milburn, Chest Clinic, Guy's Hospital, London SE1 9RT

BMJ 1998;317:856-7
The course of asthma during pregnancy is variable and may remain unchanged, worsen, or improve, returning to the pre-pregnancy state within three months after parturition. ${ }^{1}$ Some patients experience the same changes in each pregnancy, but nearly half do not, suggesting some intrinsic or extrinsic factor unique to each pregnancy such as the sex of the fetus. ${ }^{1}$ We observed that the condition of patients with moderate to severe asthma generally deteriorated when they were pregnant with girls but not boys, raising the intriguing possibility that the sex of the fetus might influence the course of asthma during pregnancy. We investigated this possibility in a blind prospective study.

\section{Subjects, methods, and results}

All women aged 25-34 who were receiving regular drug treatment for asthma and were in the second trimester of pregnancy (12-21 weeks' gestation) were approached directly to participate in the study. Twenty eight women were recruited from three hospital and four general practice antenatal clinics and six from an asthma clinic. Twelve had not taken inhaled steroids (beclomethasone or budesonide) regularly before pregnancy, 16 took 200-500 $\mu \mathrm{g}$ daily, and six more than $500 \mu \mathrm{g}$ daily. None was taking oral steroids. None knew the sex of their baby before delivery. The study took the form of a questionnaire on symptoms of asthma, cough, shortness of breath, nocturnal waking due to asthma, drug treatment (frequency and amount), and visits to a doctor for asthma before and since the beginning of pregnancy, a minimum period of 12 weeks. Subjects were also asked to keep daily diary cards and peak expiratory flow readings throughout pregnancy. All 34 subjects completed the questionnaire; only 15 agreed to keep daily records and only 6 successfully completed these. We have therefore based our analysis on the questionnaire alone. Subjects were contacted again after parturition to ascertain the sex of the baby.

Eighteen women had boys and 16 girls. There was no difference in age range of mothers, gestation at time 
of questionnaire, or severity of asthma before pregnancy between the two groups. Roughly equal numbers of mothers of boys and mothers of girls reported no change in asthmatic symptoms. However, 4 of the 18 mothers of boys reported an overall deterioration in symptoms and 8 an improvement, while 8 of the 16 mothers of girls reported an overall deterioration and none an improvement. The table shows responses to questions on individual symptoms with the results of analysis using a $2 \times 2 \chi^{2}$ test comparing proportions of subjects with deteriorating symptoms with proportions of those who improved or showed no change for mothers of boys and girls. For most questions there was a trend for greater proportions of mothers of girls to report increased symptoms and for greater proportions of mothers of boys to report an improvement in their asthma. Significant differences were found in shortness of breath, nocturnal waking, and general symptoms of asthma.

\section{Comment}

This study suggests that asthmatic women pregnant with girls are more likely than those pregnant with boys to have increased symptoms of asthma during pregnancy. Any psychological basis for this difference is unlikely as none knew the sex of her baby before delivery. All patients were questioned early in the second trimester, making it unlikely that the results were influenced by the tendency for asthma to improve late in pregnancy. ${ }^{2}$ Minute hormonal differences may be implicated. Acute exacerbations of asthma increased fourfold in women from day 26 to day 4 of the menstrual cycle, ${ }^{4}$ and injection of progesterone can reduce premenstrual asthma. ${ }^{5}$ Male fetuses produce a surge of androgens at weeks 12-16, when most of our patients completed the questionnaire.

Our limited study suggests a relation between fetal sex and the potential development of unstable asthma
Results of questionnaire survey of 34 women during second trimester of pregnancy according to sex of baby delivered. Values are numbers of women in each group

\begin{tabular}{|c|c|c|c|c|c|c|c|}
\hline & \multicolumn{2}{|c|}{ Worse } & \multicolumn{2}{|c|}{ Same } & \multicolumn{2}{|c|}{ Better } & \multirow[b]{2}{*}{$\chi^{2}(95 \% \mathrm{Cl})^{*}$} \\
\hline & Boys & Girls & Boys & Girls & Boys & Girls & \\
\hline Cough & 5 & 7 & 7 & 8 & 6 & 1 & $3.87(-48 \%$ to $16 \%) \dagger$ \\
\hline Shortness of breath & 5 & 13 & 7 & 3 & 6 & 0 & $9.72(-83 \%$ to $-23 \%) \ddagger$ \\
\hline Nocturnal waking & 6 & 10 & 5 & 5 & 7 & 1 & $5.37(-8 \%$ to $62 \%)$ 9 \\
\hline General state of asthma & 5 & 9 & 5 & 6 & 8 & 1 & $6.3(-4 \%$ to $60 \%)$ q \\
\hline Amount of drug treatment & 8 & 7 & 4 & 5 & 6 & 4 & $0.28(-33 \%$ to $34 \%)$ \\
\hline Frequency of drug treatment & 6 & 7 & 7 & 8 & 5 & 1 & $2.7(-22 \%$ to $44 \%)$ \\
\hline Visits to doctor & 3 & 5 & 10 & 11 & 5 & 0 & $3.84(-15 \%$ to $43 \%) \dagger$ \\
\hline
\end{tabular}

${ }^{*}$ Comparison of proportion of women who were worse with proportion who were not worse for boys and girls; $95 \%$ confidence interval given for difference in proportions.

$\dagger P=0.05$.

$+P<0.01$

$\mathbb{P}<<0.05$

in pregnancy, a clinically important observation for all concerned with antenatal care. This intriguing finding should stimulate further investigation.

We thank the general practitioners and obstetricians who gave us access to antenatal clinics.

Contributors: All the authors participated in designing the study. NB prepared the questionnaire, interviewed patients, and collected the data. GMC critically revised the manuscript. HJM analysed the data, wrote the paper, and had the original idea for the study and is guarantor for the study.

Funding: Abbott Laboratories gave a grant of $£ 250$ towards travelling expenses to clinics and to meet patients.

Conflict of interest: None.

1 Schatz M, Harden K, Forsythe A, Chilingar L, Hoffman C, Sperling W, et al. The course of asthma during pregnancy, post partum, and with successive pregnancies: a prospective analysis. I Allergy Clin Immunol successive pregn
1988;81:509-17.

2 White RJ, Coutts II, Gibbs CJ, MacIntyre C. A prospective study of asthma during pregnancy and the puerperium. Respir Med 1989;83:103-6.

3 Juniper EF, Daniel EE, Roberts RS, Kline PA, Hargreave FE, Newhouse MT. Improvement in airway responsiveness and asthma severity during pregnancy. Am Rev Respir Dis 1989;140:924-31.

4 Skobeloff EM, Spivey WH, Silverman R, Eskin BA, Harchelroad F, Alessi TV. The effect of the menstrual cycle on asthma presentations in the TV. The effect of the menstrual cycle on asthma presenta
emergency department. Arch Intern Med 1996;156:1837-40.

5 Benyon HLC, Garbett ND, Barnes PJ. Severe premenstrual exacerbation of asthma: effect of intramuscular progesterone. Lancet 1988;ii:370-1. (Accepted 8June 1998)

\section{A compliment \\ Having your research ideas stolen}

It was my first research project after completing my $\mathrm{PhD}$, and it required the collaboration of one large and 20 small centres. My professor and I had contacted the large centre, which will remain nameless. The director expressed interest in the study and invited us to visit and present our proposal. The potential local collaborators were eager for information: we discussed in great detail the hypothesis, the design, the sample size estimate, the questionnaires, the methods for data collection, the plan of analysis. At the end of the day came the decision: they were going to do the study without us.

It didn't turn out to be such a bad thing after all. They published their study. We published ours-based on the remaining 20 small centres-confirming their findings. Human knowledge increased a bit.

But on the way back from the meeting I struggled to come to terms with having the idea stolen. My professor seemed amused and not particularly affected. Why? "Laura, you had an idea that was good enough to steal. You will have many more ideas. It is better to be one of those whose ideas are stolen than one of those who steal ideas."

That dealt with my concern and enabled me to join in one of the most rewarding activities of science, talking shop. Discussing intriguing questions, hearing your colleagues' reaction to a new hypothesis, pointing out to students the questions that are just waiting to be answered. Of course, with time we all realise that scientific insights do not really belong to individual people, but are part of the white rapids of human knowledge. And then whose idea it was in the first place matters even less.

So the next time that you share an idea with someone and then see it in their grant proposal feel proud: it was an idea good enough to steal.

Laura C Rodrigues, senior lecturer in infectious disease epidemiology, University of London

We welcome articles up to 600 words on topics such as A memorable patient, A paper that changed my practice, My most unfortunate mistake, or any other piece conveying instruction, pathos, or humour. If possible the article should be supplied on a disk. Permission is needed from the patient or a relative if an identifiable patient is referred to. We also welcome contributions for "Endpieces," consisting of quotations of up to 80 words (but most are considerably shorter) from any source, ancient or modern, which have appealed to the reader. 